\title{
PACTO DE CONVIVÊNCIA E CONSENSO SOBREPOSTO EM RAWLS: UMA TENTATIVA DE DISCUTIR A TOLERÂNCIA NO ÂMBITO DA JUSTIÇA POLÍTICA
}

\author{
PACT OF COEXISTENCE AND CONSENSUS OVERLAID ON \\ POLITICAL THEORY OF RAWLS: AN ATTEMPT TO DISCUSS \\ TOLERANCE IN THE CONTEXT OF POLITICAL JUSTICE
}

\author{
Delmo Mattos* \\ Recebido: $12 / 2016$ \\ Aprovado: 05/2017
}

\begin{abstract}
Resumo: Na contemporaneidade, as sociedades democráticas têm que conviver com diferentes religiões, filosofias e ideologias, porquanto se torna inconcebível prescrever legalmente valores que sejam superiores em relação aos outros. Nesta perspectiva, o principal desafio do liberalismo político é explicitar uma concepção política pública de justiça que possa servir de objeto para um consenso justaposto entre as diversas e contraditórias concepções privadas de bem existentes na sociedade. A proposta desse artigo consiste em discutir os pressupostos da coexistência pacífica de uma pluralidade de doutrinas compreensivas diante de um justo equilíbrio frente ao consenso nas sociedades plurais. Para tanto, analisam-se os termos do contratualismo de Rawls no âmbito da pluralidade de escolhas. Assim, serão discutidas as determinações do princípio da cooperação social e, consequentemente, da ordem social e política para se destacar os termos do pluralismo razoável. Em seguida, destacam-se os termos do multiculturalismo e a do pluralismo para evidenciar o "consenso sobreposto" e, poder destacar os princípios daquilo que Rawls determina como um tipo de pacto de convivência acima das diferenças particulares, cujo objetivo é de tornar tais conflitos complementares e harmônicos entre si.
\end{abstract}

Palavras-chave: Pluralismo, contratualismo, liberalismo político, conflitos complementares.

\begin{abstract}
In actuality, the democratic societies have to cope with different religions, philosophies and ideologies, because it becomes inconceivable prescribe legally values that are higher than the others. In this perspective, the main challenge of political liberalism is explaining a political conception of justice that can serve as an object to a consensus juxtaposed between the various and contradictory conceptions of private well in society. The purpose of this article is to discuss the assumptions of the peaceful coexistence of a plurality of comprehensive doctrines in the face of a fair balance outside the consensus in society's plurals. To do so, it analyzes the terms of contractualism of Rawls in the context of the plurality of choices. So, be discussed the determinations of the principle of social cooperation and, consequently, of the social and political order to highlight the terms of reasonable pluralism. Then, there are the terms of multiculturalism and pluralism in order to emphasize the "consensus overlaid", and be able to highlight the principles of what Rawls determines how a type of pact of coexistence over the differences individuals, whose goal is to make such conflicts complementary and harmonious among themselves.
\end{abstract}

Keywords: Pluralism, contractualism, political liberalism, complementary conflicts.

\section{Introdução}

Ao longo da história, aponta Franco de Sá (2008, p. 23), "os Estados modernos consolidam-se enquanto tal, através da uniformização das visões

\footnotetext{
* Doutor em Ética e Filosofia Política, pela Universidade Federal do Rio de Janeiro (UFRJ). Professor da UniCeuma. Pesquisador FAPEMA e CNPq. Líder do Núcleo de Estudos em Justiça, Poder e Ética na Contemporaneidade - NEJUPEC. Realiza estágio de Pós-Doutoramento no Programa de Pós-Graduação em Direito e Instituições do Sistema de Justiça, pela Universidade Federal do Maranhão (UFMA).
}

Problemata: R. Intern. Fil. V. 8. n. 2 (2017), p. 219-236 ISSN 2236-8612

doi:http://dx.doi.org/10.7443/problemata.v8i2.32144 
compreensivas do mundo daqueles que nele coabitam". De certa forma, a homogeneização religiosa foi um fator preponderante à expulsão e à conversão forçada dos judeus na Espanha e Portugal ou, mais tarde, à expulsão dos protestantes da França, determina Franco de Sá (2008, p. 25). Não obstante, diante desse processo histórico descrito em linhas gerais, percebe-se que o problema da tolerância surge então, como objeto de tematização explícita, situado neste contexto de consolidação dos Estados europeus (FRANCO DE SÁ, 2008).

Nesse processo, várias posições que diante dele são tomadas, resultam precisamente da diferente consideração do perigo que a defesa das liberdades individuais representaria para a unidade do Estado e, consequentemente para a paz e para a segurança que somente esta mesma unidade permite. Diante disso, surge a seguinte indagação: Como alcançar a unidade de uma sociedade determinada precisamente pela ausência de unificação no plano das doutrinas compreensivas? Segundo a perspectiva de Rawls, a exigência da defesa das liberdades fundamentais dos indivíduos a que o liberalismo se consagrou, implicando a coexistência de uma pluralidade de doutrinas compreensivas, implica que a coesão da sociedade política seja assegurada por outro fator que não a partilha de uma mesma doutrina compreensiva.

Tal aspecto, na teoria de Rawls, remete-nos a uma preocupação com a coexistência pacífica de uma pluralidade de doutrinas compreensivas diante de um justo equilíbrio frente ao consenso nas sociedades plurais. $\mathrm{Na}$ contemporaneidade, as sociedades democráticas têm que conviver com diferentes religiões, filosofias e ideologias, porquanto se torna inconcebível prescrever legalmente valores que sejam superiores em relação aos outros. Nesta perspectiva, o principal desafio do liberalismo político é explicitar uma concepção política pública de justiça que possa servir de objeto para um consenso justaposto entre as diversas e contraditórias concepções privadas de bem existentes na sociedade. Diante desses critérios, o desenvolvimento das discussões desse trabalho seguirá os seguintes passos: primeiramente serão analisados os termos do contratualismo de Rawls no âmbito da pluralidade de escolhas. Assim, serão discutidas as determinações do princípio da cooperação social e, consequentemente, da ordem social e política para se destacar os termos do pluralismo razoável. Em seguida, destacam-se os termos do multiculturalismo e a do pluralismo para evidenciar o "consenso sobreposto" (overlapping consensus) e, poder destacar os princípios daquilo que Rawls determina como um tipo de pacto de convivência acima das diferenças particulares, cujo objetivo é de tornar tais conflitos complementares e harmônicos entre si. Por fim, abordam-se os termos do contratualismo e da justiça diante da temática da tolerância. Trata-se, portanto, de conceber os 
limites da tolerância enquanto característica interna das sociedades liberais no âmbito da compatibilização com os termos da justiça como equidade.

Espera-se com isso, portanto, evidenciar como os cidadãos, que continuassem profundamente divididos em relação às doutrinas religiosas, filosóficas e morais, poderia manter, apesar disso, uma sociedade democrática e estável. Para que isso ocorra, os cidadãos precisam ser concebidos como livres e iguais numa perspectiva passível de ser compartilhada por todos? Para responder a esse questionamento evidenciam-se, portanto, os termos do pluralismo e da tolerância em Rawls.

\section{Contratualismo e pluralidade de escolhas: entre o liberalismo político e o pluralismo razoável}

O ponto nefrálgico da argumentação contratualista de Rawls relaciona-se diretamente com a questão da definição dos princípios de justiça para a estrutura básica da sociedade ${ }^{1}$. Nessa perspectiva, a estrutura básica da sociedade será definida como o primeiro objeto dos princípios da justiça pelo qual as instituições mais relevantes distribuem seus direitos e deveres fundamentais, assim como determinam a divisão de vantagens oriundas da cooperação social (Cf. RAWLS, 2000a).

Sobre essa questão, comenta Rawls:

[...] a justiça é a primeira virtude das instituições sociais, como a verdade o é dos sistemas de pensamento. Embora elegante e econômica, uma teoria deve ser rejeitada ou revisada se não é verdadeira; da mesma forma, leis e instituições, por mais eficientes e bem organizadas que sejam, devem ser reformadas e abolidas se são injustas. (RAWLS, 2000a, pp. 3-4).

Diante ao exposto, a estrutura básica é o objeto primário da justiça por ser o meio pelo qual irá proporcionar aos cidadãos um ponto de partida social e econômico eqüitativo. Sobre esse aspecto, Rawls (2002a), afirma que uma teoria da justiça deve levar em conta a forma como as metas e as aspirações das pessoas são formadas, isso porque o meio de estruturação da sociedade afeta seus membros e determina o tipo de pessoas que eles querem ser, da mesma forma que determina o tipo de pessoas que eles são realmente. Nesses termos, a concepção de justiça empreendida por Rawls (2002a) constitui-se uma teoria normativa que se fundamenta por meio do argumento contratualismo, principalmente, com ênfase nas noções de justiça e não amparadas sob o aspecto da legitimidade, tal como expõe o contratualismo clássico².

$\mathrm{Na}$ perspectiva de Rawls, segundo Care (1969, p. 85), diante das condições históricas e sociais que engendraram o surgimento do Estado 
democrático liberal, como por exemplo, as guerras relacionadas à religião dos séculos XVI e XVII, não há critérios suficientes para reconhecer uma doutrina moral abrangente como moderadora da estrutura básica da sociedade. A sua explicação sobre esse fato advém, sobretudo, porque admite que "tais doutrinas admitem somente uma única concepção do bem como legítima e, portanto, aquela a ser irremediavelmente seguida por todos" (RAWLS, 1993, p. 26). Como consequência, essas doutrinas tendem a negar veementemente 0 fato do pluralismo razoável, isto é, negam a possibilidade da existência de múltiplas concepções do bem e crenças defendidas pelas pessoas numa mesma sociedade democrática liberal, que, porventura sejam conflitantes e incomensuráveis entre si, mas que sejam compatíveis com a racionalidade.

De acordo com Rawls (1993, p.22),

O liberalismo político entende o facto do pluralismo razoável como um pluralismo de doutrinas abrangentes, que inclui as doutrinas religiosas e não religiosas. Este pluralismo não é visto como um desastre, mas antes como o resultado natural das atividades da razão humana no contexto de instituições livres duradouras.

Diante desses termos, a questão proposta por Rawls (1993), em relação ao pluralismo, diz respeito ao modo como descobrir uma base pública sólida para um acordo político que seja informado e totalmente voluntário entre cidadãos livres e iguais, isto é, o modo como utilizar-se de uma base pública sólida sem utilizar-se do recurso autocrático que imponha a ordem pela força. Conforme os termos da argumentação da teoria da justiça, a estabilidade social somente poderá ser assegurada se for baseada solidamente em atitudes sociais e políticas públicas de um povo. Em relação a esse pressuposto, Rawls (2002) enfatiza a sua preocupação na resolução do problema da estabilidade através de uma investigação no qual se estabeleça um fundamento para um acordo político como uma das tarefas fundamentais da filosofia política.

Desse modo, encontrar um fundamento apropriado para o princípio da cooperação social e, consequentemente, da ordem social e política torna-se de extrema relevância para uma sociedade democrática no qual o pluralismo razoável de concepções de bem e incomensuráveis entre si convivem indiscriminadamente. Por essa razão, Rawls (2002) justifica o propósito da reflexão sobre a estabilidade baseada no argumento que essa seria, sobretudo, a tarefa mais essencial da filosofia política, cujos pressupostos teóricos estão impreterivelmente interligados ao argumento contratualista.

Em relação a esse pressuposto, na perspectiva de Kukhatas e Pettit (1999, p. 34), a função da argumentação contratualista não deve limitar somente em auxiliar a escolha dos "agentes contratantes", mas sobretudo, pacificar os conflitos e as divergências sociais. Ainda segundo Kukhatas e Pettit (1999), em 
relação ao propósito heurístico, ou seja, o fornecimento dos meios adequados no qual as pessoas possam escolher a opção viável e, portanto, a mais justa aos interesses sociopolíticos, a função do argumento contratualista de cunho estritamente hipotético, não estabelece obrigações reais, uma vez que as pessoas não são legalmente obrigadas a cumprir os termos acordados na situação hipotética. Desse modo, conforme menciona Rodilla (1986, p. 43) "a importância fornecida em relação a uma situação hipotética é, sobretudo, 0 pacificar os conflitos de interesses sociais, amenizando consequentemente as divergências sociais". Com relação a esse fato, na concepção modelo da posição original, o contrato estabelecido é imprescindível como elemento pacificador, pois através de sua hipótese contratual todos podem verificar que a escolha dos princípios de justiça e da estrutura básica da sociedade possuem realmente respaldo em um procedimento justo. Diante disso RAWLS (2002, p.16) esclarece,

Sustentarei que as pessoas na situação inicial escolheriam dois princípios bastante diferentes: o primeiro exige a igualdade na atribuição de deveres e direitos básicos, enquanto o segundo afirma que as desigualdades econômicas e sociais, por exemplo desigualdades de riqueza e autoridade, são justas apenas se resultam em benefícios compensatórios para cada um, e particularmente para os membros menos favorecidos da sociedade [...].

O que Rawls (2002) adverte é simplesmente para a concepção de que, diante de uma situação hipotética contratual, as divergências particulares e morais impedem a admissão e a escolha imparcial dos princípios de justiça como um procedimento eminentemente justo. Sendo assim, tal procedimento confronta os objetivos específicos de várias doutrinas morais ou religiosas, as quais se veem obrigadas a negar ou mutilar seus respectivos conceitos. $\mathrm{Na}$ verdade, essas doutrinas são "obrigadas a rever sua postura diante de outras doutrinas", menciona Rawls (2002). Diante desse fato, as limitações impostas pelo contrato hipotético possibilitam que as pessoas possam conviver pacificamente entre si, respeitando-se mutuamente como pessoas livres e iguais. No contexto dessa discussão, o "consenso sobreposto" ou o "consenso por sobreposição" estabelece-se como um modelo altamente relevante na perspectiva contratulalista do pluralismo, "uma vez que representa uma concepção política que recebe o apoio dos membros das diversas doutrinas", afirma Milo (1995, p. 23)

Se for realmente assim, pode-se afirmar que o modo de atuação do "consenso por sobreposição" não se limita apenas a uma mera tolerância às diferenças conforme o oportunismo ou os benefícios que tal tolerância pode acarretar. Ao contrário, o que se pode compreender é que o consenso apresenta como conteúdo, de uma concepção política, as ideias fundamentais que 
constituem a diversidade da cultura pública democrática. Nesse contexto, a proposta evidenciada por Rawls (2002) implica nada mais do que a disponibilidade de determinados valores culturais de uma determinada doutrina abrangente agregada respectivamente a diversos outros valores de distintas doutrinas resultem, incontestavelmente, no significativo conteúdo de uma concepção política, a qual identifica em todas as concepções do bem os elementos racionais e razoáveis mais adequados aos propósitos democráticos ${ }^{3}$.

Seguindo os termos dessa interpretação, o liberalismo político proposto por Rawls, tal como explica Kukathas e Pettit (1999), compreende um determinado liberalismo que não depende de nenhum ideal moral liberal em particular, como a autonomia, por exemplo. Diante dessa constatação, para os referidos intérpretes o liberalismo do filósofo em questão não se distancia do que se concebe por liberalismo, o que diferencia é a sua observância relativa a importância da tolerância e, sobretudo, da defesa de um sistema de governo orientado por princípios que não pressupõem uma determinada forma de boa vida como a sendo realmente a melhor.

Do que foi mencionado, nada mais coerente do que posicionar o "overlapping consensus" na função de assegurar a estabilidade numa sociedade no qual o pluralismo é o resultado inevitável do funcionamento das instituições livres e do uso pleno da razão, ao passo que representa uma concepção de legitimidade política. Como consequência desse fato, infere-se a possibilidade do reconhecimento de que os cidadãos sejam realmente livres e iguais e, mediante esse reconhecimento, possam efetivamente pensar a possibilidade de que toda concepção liberal deva proceder em um exame da sua própria estabilidade, de tal modo que cada cidadão possa afirmá-la livremente. Na perspectiva de Weber, (2011 p. 137)

\footnotetext{
Pode-se observar que o campo de abrangência da Filosofia Política em Rawls, aqui, é claro. Para chegar a um consenso ela deve manter independência e autonomia em relação aos problemas e controvérsias de outras áreas da Filosofia, como por exemplo, os ligados à religião, às questões morais, etc. Essa independência não significa indiferença ou ceticismo. Para obter o respaldo (acima referido) a concepção de justiça deve ocupar-se de valores políticos essenciais e endossáveis.
}

Uma vez dito isso, uma indagação se impõe imediatamente em relação a esse pressuposto: se pluralismo constitui-se em uma característica fundamental das sociedades democráticas modernas, torna-se possível, da mesma forma, redimensioná-lo como um dos fundamentos básicos de uma concepção de justiça social? Se for dessa forma, uma concepção de justiça social, ou seja, a justiça como equidade, terá de estabelecer um fundamento que viabilize a cooperação entre os defensores de diferentes doutrinas abrangentes? Esse será, portanto, a proposta de Rawls quando reflete as determinações do 
"consenso por sobreposição". Sobre esse ponto da argumentação, Guillarme $(1996,326)$ esclarece:

\begin{abstract}
O consenso por sobreposição é um mecanismo de justificação das instituições políticas e jurídicas, fazendo com que a sociedade adote uma pauta mínima de valores, cuja adesão seja a mais ampla entre seus diversos segmentos, independentemente do credo religioso, da orientação político-ideológica ou da filosofia de seus integrantes. A existência de um consenso sobreposto é sinal de pluralismo e democracia, bem assim de valores liberais (o que não pode ser confundido com o sentido do liberalismo econômico).
\end{abstract}

A concepção política de justiça apresentada por Rawls fornece adequadamente uma resposta condizente para o problema do pluralismo nas sociedades contemporâneas, pois apresenta a justiça como a qualidade mais importante nas instituições ${ }^{4}$. De certa forma, essa qualificação da justiça elevaa a uma discussão preponderante na temática da filosofia política, uma vez que a legitimidade de uma democracia não suprime possíveis injustiças das decisões para determinados grupos, nem ao menos garante estruturas confiáveis em relação à ótica da justiça para questões de distribuição de direitos e deveres. Com efeito, por meio da construção de um espaço ampliado de debate denominado "razão pública", Rawls (2002) sustenta que, uma sociedade bemordenada não pode existir, sem um espaço ampliado de participação para que cidadãos livres e iguais discutam sobre aspectos essencialmente relacionados aos problemas decorrentes da justiça.

De fato, Rawls ao elaborar uma concepção de justiça no qual possibilita conciliar as diferentes visões de mundo em torno de um elemento comum objetivando obter um consenso por sobreposição de doutrinas abrangentes razoáveis, não possui, portanto, qualquer pretensão de se declarar a única visão correta, de modo a excluir todas as demais ${ }^{5}$. A sua proposta nada mais é do que a de aplicar na filosofia o princípio da tolerância. Diante do fato do pluralismo, a elaboração de uma concepção de justiça não deve basear-se em doutrinas abrangentes que sejam absolutamente incapazes de proporcionar uma base adequada para o acordo entre os cidadãos de uma comunidade, razão pela qual a teoria da justiça deve descartar visões metafísicas, limitando-se consequentemente a construir concepções políticas de justiça (DIETERLEN, 1992).

\title{
Multiculturalismo, contratualismo e pluralismo: o sentido do "consenso de sobreposição" no âmbito da tolerância
}

Seguindo essa determinação, na formulação final da teoria da justiça, 
pode-se conceber que a construção do valor do justo não se baseia em nenhuma crença particular, mas sim em valores políticos que são comuns a todos. Nesse caso, o problema fundamental da justiça consiste, sobretudo, na busca de uma base mínima de acordo que respeite os princípios contidos na constituição, embora esse seja o único elemento em torno do qual se pode obter um consenso em uma sociedade democrático-pluralista. Em outros termos, expõe Dieterlen (1992, p. 12) "através da ideia de um consenso por sobreposição que se realiza inicialmente a justificação pelo qual a sociedade moderna, caracterizada pelo fato do pluralismo razoável, pode alcançar posteriormente a justificação pública". Essa justificação, por sua vez, garante as bases de uma unidade social duradoura e profunda de uma sociedade caracterizada, sobretudo, pelo fato de constituir-se pelo pluralismo e pelo multiculturalismo.

Desse modo Rawls (1999, p. 84),

\begin{abstract}
Deixamos de lado as doutrinas abrangentes que existem hoje, que já existiram ou que podem vir a existir. A ideia não é que os bens primários são equitativos em relação às concepções abrangentes do bem associadas a essas doutrinas, por determinarem um equilíbrio equitativo entre elas, mas sim que são equitativas em relação a cidadãos livres e iguais, enquanto pessoas que tem essas concepções.
\end{abstract}

Por sua vez, segundo Altable (1995. p. 136), "a tolerância e seus limites somente se justificam se estão emparelhadas com o princípio da igual liberdade, e jamais se justificam por razões meramente pragmáticas, nem ao menos por doutrinas filosóficas ou metafísicas". Sendo assim, qualquer que seja imposta uma limitação à liberdade apenas poderá justificar-se a fim de evitar uma injustiça maior. Por outro lado, a restrição as razões compartilháveis por todos não significam, porém, que a teoria da justiça considere suas respectivas razões como realmente superiores aos motivos religiosos ou filosóficos, nem é a eles indiferente ou cética (RAWLS, 2005a, p. 214).

O propósito de Rawls, por conseguinte, não consiste em negar em absoluto tais doutrinas, mas esquivar-se de maiores pressuposições em favor de uma política acessível a todos. Com efeito, conforme destaca o filósofo, os intolerantes devem ser tolerados pelo mesmo motivo da tolerância de outras doutrinas, ou seja, sem qualquer impedimento ou supressão das suas respectivas liberdades religiosas ${ }^{6}$. Em relação a esse pressuposto, o Estado, na sua racionalidade, deve proteger a liberdade fundamental dos indivíduos de escolher livremente seus projetos de vida. Nesse contexto, a mera intolerância não é razão para suprimir uma doutrina (RAWLS, 2000).

Diante dos termos elencados, adianta Audard (2000), a concepção de consenso de sobreposição, ainda esteja relacionada à estabilidade da teoria, torna-se, por conseguinte um elemento imprescindível de justificação no âmbito da teoria da justiça ${ }^{7}$. Portanto, na ausência desse elemento teórico, a concepção 
de justiça não seria amplamente justificada, apesar do respaldo da posição original. Diante dessa relevância conceitual, Rawls legitima a questão da estabilidade ao conectá-la a questão de uma legitimidade liberal, a qual, segundo ele próprio afirma é "assegurada com motivação suficiente e adequada, adquirida sob instituições justas” (RAWLS, 2000, p. 142).

$\mathrm{Na}$ perspectiva do filósofo, a justiça como equidade somente poderia ser considerada razoável se ao menos estiver atrelada às razões de cada cidadão. Nesse caso, considerar-se-ia a sua concepção política de justiça como um módulo que pode perfeitamente encaixar-se e apoiar-se em algumas dessas doutrinas que sejam evidentemente razoáveis (RAWLS, 2000, p. 144). Tal "módulo" evidenciado, no contexto da justiça, explica irremediavelmente o sentido do consenso de sobreposição. Desse modo, conforme afirma Audard (2007, p. 197), "o consenso de sobreposição é o estável e duradouro acordo entre doutrinas abrangentes razoáveis, no qual cada uma apoia a concepção de justiça a partir de seu próprio ponto de vista”. Segundo Zambam (2004, p. 89)

\begin{abstract}
O consenso se dá no campo da política e recebe o respaldo das principais instituições. Especial destaque deverão ter os valores políticos fundamentais que estão expressos nos princípios e ideais dos membros da sociedade. Em torno dos valores políticos devem ser formulados os acordos, pois neles se manifestam as divergentes doutrinas compartilhadas no interior da sociedade. É preciso ressaltar que, para o liberalismo político, é inconcebível o uso do poder político para impor doutrinas abrangentes próprias, sejam elas de natureza religiosa, filosófica ou moral.
\end{abstract}

Considerando, por sua vez, essa pressuposição, Rawls (2000, p. 153) concebe o sentido no qual a tolerância é aplicada à própria filosofia na medida em que propõe "deixar os próprios cidadãos resolverem as questões de religião, filosofia e moral de acordo com as visões que eles livremente afirmam". Nesses termos, os cidadãos são persuadidos a apoiar o consenso de sobreposição "seja como verdadeiro, seja como razoável, do modo como a visão [abrangente] permitir" (RAWLS, 2000, p. 151). Portanto, a concepção abrangente pluralista considera, por conseguinte, haver "diferentes domínios de valor, dos quais o político é somente um deles", afirma Rawls (2000, p. 170).

Nesses termos, o acordo prudencial entre as visões abrangentes e 0 Estado reflete, na concepção de Rawls, um equilíbrio de razões do ponto de vista das doutrinas abrangentes dos cidadãos, na medida em que lhes permitem respeitar os valores políticos e os limites da razão pública. Diante desse contexto, Zambam (2004) evidencia que o próprio cidadão que decidirá o que considera ser a sua respectiva perspectiva de justiça verdadeira, ou simplesmente razoável. Tal consideração explica, por conseguinte, a proposta de Rawls de buscar uma base ampla de apoio para a concepção de justiça, evitando aproximar-se de determinadas controvérsias filosóficas, morais e 
religiosas. Não obstante, na visão de Kymlicka (1996, p. 46), tal apoio seria impossível no âmbito da política liberal, pois aceitar a autonomia em contextos políticos inevitavelmente possibilita o seu exercício mais geral.

Desse modo Cittadino (2000, p. 1),

O pluralismo, entretanto, possui, pelo menos, duas significações distintas: ou o utilizamos para descrever a diversidade de concepções individuais acerca da vida digna ou para assinalar a multiplicidade de identidades sociais, específicas culturalmente e únicas do ponto de vista histórico.

Tal consideração desenvolvida por Kymlicka (1996) remete-se diretamente a acusação dos críticos de Rawls de que a teoria da justiça corresponderia a uma espécie de doutrina abrangente e, portanto, incapaz de conciliar-se com o fato do pluralismo. Esta interpretação está diretamente relacionada à demonstração da concepção de justiça como equidade como integrante de uma teoria moral que, por conseguinte, desvelaria uma doutrina filosófica ainda maior. Não obstante, o que consequentemente direciona o empreendimento político de Rawls quando o mesmo propõe uma discussão sobre liberalismo, mais precisamente sobre liberalismo político, é a sua concepção de pluralismo. Obviamente, essa preocupação não é despretensiosa, uma vez que a questão da tolerância acompanha todo o debate político da sua contemporaneidade tornando, por conseguinte, uma das grandes preocupações de Rawls, não só no âmbito da sua análise política interna, como também nas questões da política internacional.

Segundo evidencia Pogge (2007), torna-se imprescindível uma atenção maior a qualquer referência ao conceito de tolerância antes, porém, de especificar a qual tipo de pensamento liberal está se remetendo. O motivo dessa atenção refere-se particularmente a ênfase fornecida, pelo liberalismo rawlsiano à ideia de pluralismo, uma vez que o modo como o filósofo enfatiza o liberalismo, através do conceito de justo, demonstra a sua preocupação sem, no entanto, remeter-se ou aproximar-se cair aos termos do autoritarismo. Como base nisso, fica evidente, a relação sugerida por Rawls entre os termos do liberalismo político e as determinações de uma sociedade constituída pela pluralidade, pelo qual se torna imprescindível os princípios de liberdade e igualdade (POGGE, 2007, p. 23).

Em outros termos, o pressuposto fundamental do liberalismo político, tal como expressa Rawls, é o modo como a sociedade contemporânea considerada plural determina seus respectivos princípios de liberdade e igualdade, sem que haja uma imposição de uma doutrina sobre as demais. Uma vez determinado essa questão, Rawls respalda-se teoricamente na consecução da diferenciação que entre o liberalismo político e os liberalismos abrangentes. Portanto, a 
obtenção dessa distinção deve necessariamente a pressuposição de que a ideia de tolerância permanece um desafio para as instituições políticas nas sociedades hodiernas, cujas características mais marcantes são a pluralidade e multiculturalidade (DIETERLEN, 1992). Diante disso, pode-se conceber que as soluções fornecidas por Rawls, no contexto da relação entre justiça, pluralismo e contratualismo, não devem ser consideradas como definitivas, mas, sobretudo, como elementos fundamentais para enriquecer debate sobre essa questão tão necessariamente polêmico e norteador para a solidificação do ambiente democrático nas sociedades contemporâneas.

\title{
Contratualismo, justiça e tolerância: a pluralidade em questão
}

No âmbito de cenário atualmente influenciado por imagens de mundo de cunho naturalista e, paradoxalmente, por uma influência crescente do setor das ortodoxias religiosas nas questões políticas, os pressupostos normativos do Estado democrático de direito encontram-se sob nova configuração. A tolerância enquanto característica interna das sociedades liberais surge no pensamento de Rawls (2002) como um mecanismo fundamental para responder a um tema tão antigo quanto presente nas sociedades atuais: o conflito entre diferentes e racionáveis doutrinas compreensivas do que venha a ser uma vida feliz e virtuosa, porém incompatíveis entre si. Diante disso, supõe-se que os grupamentos humanos, o mais provável é que existam diferentes maneiras de se entender o que é bom. Segundo Rodilla (1996, p. 23), se considerarmos que há diferentes propostas de bem e que todas podem oferecer justificativas suficientes e racionalmente válidas, a questão que se apresenta é de como devemos harmonizá-las numa sociedade liberal, isto é, numa sociedade que prime pela liberdade individual e pela igualdade de oportunidades.

Segundo Rawls (RAWLS, 2000, p.33):

\begin{abstract}
A origem histórica do liberalismo político (e do liberalismo em geral) está na Reforma e em suas consequências, com as longas controvérsias sobre a tolerância religiosa nos séculos XVI e XVII. Foi a partir daí que teve início algo parecido com a noção moderna de liberdade de consciência e pensamento. (...) Antes da prática pacífica e bem sucedida da tolerância em sociedades com instituições liberais, não havia como saber da existência dessa possibilidade. (...) A intolerância era aceita como uma condição da ordem e estabilidade sociais. O enfraquecimento dessa idéia ajuda a preparar o terreno para as instituições liberais.
\end{abstract}

Neste sentido, a tolerância ganha destaque, ainda que indireto, no contexto da teoria da justiça de Rawls. Segundo o filósofo, as diferentes doutrinas compreensivas de bem devem estar articuladas numa concepção 
moral de justiça para a estrutura básica de uma sociedade (RODILA, 1986). Assim, o bom pode se expressar de diversas maneiras se, e somente se, articulados com o justo. Por outro lado, a justiça, enquanto pressuposto e primazia, fundamenta e orienta o pluralismo numa sociedade liberal. Desse modo, Rawls nos indica tangencialmente a sua concepção de tolerância. Segundo Pogge (2007, p. 26), pode-se destacar no pensamento de Rawls cinco diferentes considerações sobre a tolerância, que, de fato, correspondem e confirmam o liberalismo político: (1) tolerância como resultado de uma justa e igualitária liberdade de consciência e de expressão; (2) tolerância como o mais adequado método de confronto entre diferentes doutrinas compreensivas de bem numa sociedade pluralista; (3) tolerância enquanto recurso político de defesa das liberdades individuais contra um Estado intolerante ou contra grupos intolerantes dentro de uma sociedade liberal; (4) tolerância como virtude democrática dos cidadãos no uso da razão pública e na apresentação de argumentos no fórum político e (5) tolerância enquanto abstenção dos povos liberais de impor à força os princípios liberais aos povos não liberais. (MILO, 1992, p. 181).

Portanto, segundo essa perspectiva, na visão de Rodilla (1996), todas as vezes que surge uma questão de tolerância, relativa ao gozo e exercício dos direitos ou bens primários na estrutura básica da sociedade, deve-se lançar mão do princípio da distribuição, de modo que o valor menor da liberdade seja compensado. Esse paradigma distributivo deve ter como fundamento os próprios princípios de justiça, de forma que "quando pessoas de convicções diferentes apresentam à estrutura básica da sociedade exigências conflitante, devido a princípios políticos, essas reivindicações devem ser decididas em conformidade com os princípios da justiça" (RAWLS, 2002, p. 240). Como conseqüência desse argumento, interpreta-se que, tendo em vista a imprescindibilidade do acesso aos bens primários fundamentais, tem-se que, na concepção de Rawls, qualquer crença cultural que negue ou dificulte o total acesso a qualquer tipo desses bens não pode ser objeto de tolerância, motivo pelo qual se justifica a caracterização da doutrina dos bens primários como um primeiro limite para tolerância.

De modo geral, pode-se afirmar que as doutrinas liberais da tolerância partem da idéia de que o pluralismo é uma característica inerente, inevitável e salutar da sociedade liberal. Entretanto, o modo de lidar com essa espécie de pluralismo muda no decorrer de cada teoria. No caso do Rawls, segundo Rodilla (1996, p. 23), as questões de tolerância encontram sua solução nos dois princípios de justiça como equidade, isto é, na aplicação de uma espécie de paradigma distributivo. Esse paradigma, por sua vez, possui limites estritos, que determinam até que ponto é possível estender a concepção de Rawls sobre a tolerância. Isso indica que o objetivo da sua teoria não é fazer uma apologia à 
eliminação ou diminuição das diferenças econômico-sociais, mas sim determinar o que significa uma diferença justa. Entretanto, a teoria de tolerância que surge do princípio da distribuição pode ser eficaz em alguns momentos, mas não é capaz de resolver todas as questões de tolerância (MILO, 1992).

\section{Considerações finais:}

As discussões proferidas ao longo desse trabalho evidenciaram a preocupação de Rawls com a coexistência pacífica de uma pluralidade de doutrinas compreensivas remete a uma preocupação com o justo equilíbrio frente ao consenso nas sociedades plurais. Desse modo, o filósofo reflete sobre as demandas das sociedades democráticas baseadas na possibilidade de convivência com diferentes religiões, filosofias e ideologias, e a sua relação com a prescrição de valores que sejam superiores em relação aos outros. Nesse sentido, o desafio do liberalismo político consiste, nada mais do que explicitar uma concepção política pública de justiça que possa servir de objeto para um consenso justaposto, entre as diversas e contraditórias, se bem que razoáveis concepções privadas de bem existentes na sociedade (RODILLA, 1996).

Desse modo, ao abordar a noção de "consenso sobreposto", Rawls, afirma que o pluralismo razoável já está incluído dentro da busca por equidade na justiça. Esse pluralismo razoável, nada mais é que a diferença da concepção política de justiça para cada cidadão, dentro das diversas linhas de pensamentos filosóficos, religiosos e morais. No entanto, mesmo diante da pluralidade de pensamentos, isso não significa dizer que não haja um denominador para a realização da justiça. Pelo contrário, as diferenças, segundo Rodilla (1996, p. 34), embora não opostas, mas razoáveis, tornam a justiça ainda mais importante dentro da diversidade de doutrinas seguidas pelos cidadãos.

A partir do "consenso sobreposto" do liberalismo político, as doutrinas, religiosas e não-religiosas, sustentam uma concepção política de justiça, baseada em uma sociedade democrática constitucional. No "consenso sobreposto", as doutrinas razoáveis endossam a concepção política, partindo cada uma de seu próprio ponto de vista. Mas por que se busca a resolução de conflitos entre doutrinas abrangentes e razoáveis? Porque, para Rawls, as sociedades necessitam de estabilidade, permitindo a legitimidade das regras, procedimentos e ações sociais (MILO, 1992). Estabilidade não significa induzir os que rejeitam determinada concepção a aceitá-la ou agir de acordo com ela por meio de sanções efetivas, impondo formas de aceitação. Ao contrário, buscase na legitimidade política uma base pública de justificação apelando para a razão de cidadãos livres e iguais, considerados razoáveis e racionais (RODILLA, 
1996, p. 23)

Diante disso, ficam evidentes que a pluralidade de culturas e doutrinas são partes essenciais dentro da formação de "consenso sobreposto". Assim, o indivíduo, de acordo com seu histórico de vida, tem noções diferentes de justiça, com isso demandas diferente surgem. Somente com essa multiplicidade de pensamentos que podemos dialogar para alcançar a justiça como equidade.

\section{Referências bibliográficas}

BARRY, Brian. "John Rawls and the search for stability". Ethics, vol. 105, n. 4, p. 874-915, jul. 1995.

Justice as impartiality. Oxford: Clarendon Press, 1995.

ALTABLE, María Pilar González. Liberalismo vs. Comunitarismo (John Rawls: una concepción política del bien). In: Doxa. Cuadernos de Filosofía del Derecho. n. 17-18. Madrid: Universidad de Alicante, 1995. p. 117-136.

AUDARD, Catherine. Introdução: John Rawls e o conceito do político. In: RAWLS, John. Justiça e democracia. Tradução por Irene A. Paternot. São Paulo: Martins Fontes, 2000, p. XIII-XXXVII. (Coleção Justiça e Direito).

BRAGA, A. F. S. Kant, Rawls e o utilitarismo: justiça e bem na filosofia contemporânea. Rio de Janeiro, Contraponto, 2011.

BROWNE, D. E., "The Contract Theory of Justice", Philosophical Papers 5 (1976):1-10.

BRUDNEY, Daniel. Hypothetical Consent and Moral Force, Law and Philosophy. 10 (1991):235-70.

BENTHAN, Jeremy, 1748, Uma Introdução aos Princípios da Moral e da Legislação/Jeremy Bentran. Tradução LuizJoão Baraúna. Nova Cultural.1989.

BEITZ, C. Rawls's Law of Peoples. Ethics, Vol.4, №110, 1999.

BOEIRA, Nelson. Sobre a deliberação em questões públicas. In Nythamar Fernandes de Oliveira e Draiton Gonzaga de Souza. Justiça e Política. Homenagem a Otfried Hoffe. Porto Alegre: EDIPUCRS, 2003. 
CARE, Norman S. Contractualism and Moral Criticism, Review of Metaphysics 23(1969):85-101.

DIETERLEN, Paulette, "La filosofía política de John Rawls", Revista Mexicana de Ciencias Políticas y Sociales, nueva época, año XXXVII, núm. 150, octubrediciembre de 1992.

DANNER, Leno Francisco. O Fato do Pluralismo em Rawls: sobre a Fundamentação da Sociedade Política. Revista Estudos Filosóficos oㅡ 5 /2010 p. $155-173$.

FERRAZ, Sérgio. Modelos de Sociedades Justas: Rawls e a tradição utilitarista. Ágora filosófica, Ano 11, n. 2, jul./dez. 2011. pp. 123-157.

FRANCO DE SÁ, A. O problema da tolerância na filosofia política de John Rawls. Corvilhã: Lusofia, 2008.

GUILLARME, Bertrand. Rawls et le libéralisme politique. In: Revue Française de Science Politique. Volume 46: Pluralisme, Justice, Égalité - de lémpirique au philosophique dans l'étude de la démocratie, n. 2, abr. 1996. p. 321-43.

KOLM, Serge-Christophe. Teorias modernas da justiça. Tradução Jefferson Luiz Camargo e Luís Carlos Borges. São Paulo: Martins Fontes, 2000.

KYMLICKA, Will. Multicultural Citizenship. Inglaterra: Oxford University Press, 1996;

MILLER, Richard. "Rawls, Risk, and Utilitarianism", Philosophical Studies 8 (1975):55-61.

MILO, Ronald. Contractarian Constructivism. Journal of Philosophy 122. (1995):181-204.

HENNIGFELD, Jochem; JANSOHN, Heinz (Org.). Filósofos da atualidade: uma introdução. São Leopoldo: Ed. UNISINOS, 2006.

JORDÃO, Marco Aurélio de Medeiros. O justo como proposta de superação. Revista Opinião Filosófica, Porto Alegre, v. 03; №. 02, 2012.

KUKATHAS, Chandran e PETTIT, Philip. Rawls, Uma Teoria da Justiça e seus 
críticos. Tradução por Maria Carvalho. Lisboa: Gradiva Publicações, 1990.

OLIVEIRA, Nythamar. Rawls. Rio de Janeiro: Jorge Zahar, 2003.

POGGE, Thomas. John Rawls: His Life and Theory of Justice. Oxford: Oxford University Press, 2007.

. "On Justification". In: POGGE, Thomas. John Rawls: His Life and Theory of Justice. Oxford: Oxford University Press, 2007, p. 161-177.

RAWLS, John. Uma teoria da justiça. 2. ed. São Paulo: Martins Fontes, 2002.

. O liberalismo político. Trad. Dinah de Abreu Azevedo. São Paulo: Editora Ática, 2000.

- Justiça e democracia. Tradução de Irene A. Paternot. São Paulo:

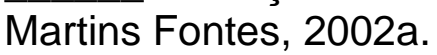

The Sense of Justice. In: Collected Papers (Org. Samuel Freeman) Cambridge-Massachussets: Harvard University Press, 1999.

RODILLA, Miguel Angel. Presentacion. In: RAWLS, John. Justicia como equidad - materiales para una teoria de la justicia. Traducción Miguel Ángel Rodilla. Madrid: Editorial Tecnos, 1986 (Biblioteca Universitaria). p. IX-L.

SCARR, Geoffrey. Utilitarianism. Ted HONDERICH (ed.). Problems of Philosophy. London: Routledge, 1996.

SCANLON, Thomas. Rawls 'Theory of justice'. In: DANIELS, Norman. Reading RAWLS: critical studies on Rawls' A Theory of justice. New York: Basic Books, s.d., cap. 8, pp. 169-205

VITA, Álvaro de. A justiça igualitária e seus críticos. São Paulo: Unesp, 2002, capítulo 6, pp. 207-276

. O liberalismo igualitário: sociedade democrática e justiça internacional. São Paulo: Martins Fontes, 2008, cap. I, pp. 21-60

VALLESPÍN OÑA, F. Nuevas Teorías del Contrato Social: John Rawls Robert Nozick y James Buchanan, Alianza, Madrid, 1985. 
WEBER, T. Autonomia e consenso sobreposto em Rawls. Ethic@- Florianópolis, v. 10, n. 3, p. 131 - 153, Dez. 2011.

\author{
ZAMBAM, Neuro José. A teoria da justiça de John Rawls: uma leitura. Passo \\ Fundo: Ed. UPF, 2004.
}

\begin{abstract}
${ }^{1}$ Na sua obra A Theory of Justice, Rawls expõe de forma contundente a pretensão de superação do pensamento utilitarista: "Meu objetivo é elaborar uma teoria da justiça que represente uma alternativa ao pensamento utilitarista em geral e consequentemente a todas as suas diferentes versões. Portanto, ao abandonar os princípios utilitaristas e retomar a tradição do contrato social, Rawls sobrepõe o conceito de justiça como equidade ao conceito utilitarista de justiça como maximização do bem-estar" (2000a, p. 25).

${ }^{2}$ Cabe notar que, na obra Justice as Fairness: A Restatement, Rawls distingue três níveis de justiça: a justiça local (compreende os princípios que se aplicam as associações, grupos e arranjos sociais existentes no interior da estrutura básica); a justiça doméstica (abrange os princípios que devem regular a estrutura básica da sociedade). Verificar: RAWLS (2003).

${ }^{3}$ As denominadas "doutrinas abrangentes" são sistemas e perspectivas de vida coerentes dados por visões de mundo, de pessoa e de sociedade, valores, e crenças comuns sobre como as coisas devem ser. As pessoas têm afeições, saberes e devoções, dos quais não poderiam se distanciar para avaliá-los com objetividade. Seria mesmo impensável alguém sem vínculos de lealdade, convicções religiosas, filosóficas e morais.

${ }^{4}$ Sobre a concepção de justiça Rawls menciona (2002, pp. 3-4): “A justiça é a primeira virtude das instituições sociais, como a verdade o é dos sistemas de pensamento. Embora elegante e econômica, uma teoria deve ser rejeitada ou revisada se não é verdadeira; da mesma forma leis e instituições, por mais eficientes e bem organizadas que sejam devem ser retomadas ou abolidas se são injustas. Cada pessoa possui uma inviolabilidade fundada na justiça que nem mesmo o bem-estar da sociedade como um todo pode ignorar. Por essa razão, a justiça nega que a perda da liberdade de alguns se justifique por um bem maior partilhado por outros. Não permite que os sacrifícios impostos a uns poucos tenham menos valor que o total maior das vantagens desfrutadas por muitos. Portanto uma sociedade justa as liberdades da cidadania igual são consideradas invioláveis; os direitos assegurados pela justiça não estão sujeitos à negociação política ou ao cálculo de interesses sociais. A única coisa que nos permite aceitar uma teoria errônea é a falta de uma teoria melhor; de forma análoga, uma injustiça é tolerável somente quando é necessária para evitar uma injustiça ainda maior. Sendo virtudes primeiras das atividades humanas, a verdade e a justiça são indissociáveis".

5 "A existência de doutrinas que negam uma ou mais liberdades democráticas é, por si, um fato permanente da vida, ou assim parece. Isso nos impõe a tarefa prática de contê-las - como se contém uma guerra ou uma doença-, para que não subvertam a justiça política" (Rawls: 2000, nota 19 da conferência II).

6"Desse modo, como os cidadãos têm capacidades morais, eles são, de certo modo, responsáveis não só pela sua formação, como também pela manutenção de seus objetivos finais e pelas suas preferências. É isso que o uso dos bens primários pressupõe. Mesmo se o indivíduo tiver preferências, digamos, extravagantes, ele é responsável por suas escolhas e predileções; com isso, não se pode considerar
\end{abstract}


tais sujeitos como passíveis de seus desejos, mas cidadãos cujas escolhas são parte de uma formação moral” (JORDÃO, 2012, p. 152).

7"O argumento a favor dos dois princípios da justiça não supõe que as partes têm objetivos particulares, mas apenas que elas desejam certos bens primários. São coisas que é racional desejar, independentemente de outros desejos. Assim, dada a natureza humana, desejá-las faz parte de ser racional; e embora se presuma que cada um tenha alguma concepção da felicidade, nada se sabe sobre os objetivos finais de cada um. A preferência por bens primários é derivada, portanto, apenas das suposições mais gerais sobre a racionalidade e sobre as condições da vida humana. Agir com bases nos princípios da justiça é agir com base em imperativos categóricos, no sentido de que eles se aplicam a nós, quaisquer que sejam os nossos objetivos particulares. Isso simplesmente reflete o fato de que nenhuma dessas contingências aparece como premissa em sua dedução" (RAWLS, 2002, p.277-8).

Problemata: R. Intern. Fil. v. 8. n. 2 (2017), p. 219-236

ISSN 2236-8612 